University of Nebraska - Lincoln

DigitalCommons@University of Nebraska - Lincoln

\title{
A ballistic material model for continuous-fiber reinforced composites
}

Chian-Fong Yen

U.S. Army Research Laboratory, chianfong.yen@us.army.mil

Follow this and additional works at: https://digitalcommons.unl.edu/usarmyresearch

Yen, Chian-Fong, "A ballistic material model for continuous-fiber reinforced composites" (2012). US Army Research. 235.

https://digitalcommons.unl.edu/usarmyresearch/235

This Article is brought to you for free and open access by the U.S. Department of Defense at DigitalCommons@University of Nebraska - Lincoln. It has been accepted for inclusion in US Army Research by an authorized administrator of DigitalCommons@University of Nebraska - Lincoln. 


\title{
A ballistic material model for continuous-fiber reinforced composites
}

\author{
Chian-Fong Yen* \\ U.S. Army Research Laboratory, Aberdeen Proving Ground, MD 21005, United States
}

\section{A R T I C L E I N F O}

\section{Article history:}

Received 10 November 2010

Received in revised form

27 December 2011

Accepted 28 December 2011

Available online 30 January 2012

\section{Keywords:}

Ballistic impact

Composite materials

Damage mechanics

Material model

Rate effect

\begin{abstract}
A B S T R A C T
A ply-level material constitutive model for plain-weave composite laminates has been developed to enable computational analyses of progressive damage/failure in the laminates under high velocity ballistic impact conditions. In this model, failure-initiation criteria and damage evolution laws are introduced to account for the major fiber-failure modes (tensile, compressive, punch shear and crush loading). In addition, two matrices related failure modes (in-plane shear and through the thickness delamination) are also accounted for. These types of fiber and matrix failure modes are commonly observed during a ballistic event. The composite-material model has been implemented within LS-DYNA as a user-defined material subroutine and used successfully to predict the damage and ballistic behavior of composite laminates subjected to various ballistic impact conditions. It is hoped that the availability of this material model will help facilitate the development of composite structures with enhanced ballistic survivability.
\end{abstract}

Published by Elsevier Ltd.

\section{Introduction}

Composites have long been used in personnel and vehicle protective/structural applications for protection against various ballistic and blast threats. Composite materials are well suited to this role because of their superior stiffness and strength-to-weight properties over many other classes of materials. Utilization of composite materials provides mass efficiency with enhanced survivability for various combat vehicles and protection devices. To rapidly develop novel protective systems, it is essential to employ advanced numerical simulations together with experimental evaluation to assess a range of material and structural solutions. However, in order to accurately capture the protective performance using numerical simulations, the composite material behavior must be modeled correctly. Toward this goal, a robust material model for composites subjected to blast and ballistic impact has been developed and validated by the author in preceding decades [1-4]. This paper reports an extension of the previous work to include a unidirectional model together with the validation of modeling composite ballistic behavior using newly acquired material and ballistic test data.

While composites have been effectively used in personnel and vehicle protection since World War II, modeling the progression of damage and ultimate failure caused by blast and ballistic impact

\footnotetext{
* Tel.: +1 410306 0732; fax: +1 4103060759 .

E-mail address: chianfong.yen@us.army.mil.
}

has only been developed since the 1980's. This is due to the enormous complexity of the material loading and failure that occurs when a composite is impacted and perforated. During ballistic impact, composite laminates absorb energy primarily due to the failure of fibers under axial tension/compression, punch shear and crush loading. Failure modeling of composite materials under impact loading has been the subject of numerous studies [5-8]. However, few studies have been reported on modeling progressive damage/failure in composites under high strain rate ballistic loading. The composite failure model originally adopted within LS-DYNA is the Chang-Chang [9] model (MAT 22), which provides various fiber and matrix failure modes solely due to in-plane stresses in unidirectional lamina. In this 2D failure model, the failure mode due to out-of-plane shear and normal stresses are neglected. While this may be sufficient for composite structures under in-plane loading, this model is not expected to adequately represent composite material response under transverse impact loading conditions during which all six stress components are known to contribute to damage/failure development.

A continuum damage mechanics (CDM) model for unidirectional composite layers based on plane-stress state was reported by Matzenmiller et al. [10]. Studies reported by William and Vaziri [11] and Van Hoof et al. [12], have shown that CDM-type post failureinitiation models can significantly improve the prediction of impact progressive damage/failure in composite structures. Note that non-interactive failure criteria (based on maximum strain assumption) due to tension, punch shear and crush loading were originally proposed by Van Hoof et al. [12], to account for the major 
failure modes accompanying ballistic impact of composite materials. This model, however, neglects the rate dependency of the material response. The same deficiency, i.e., a lack of accountability for the strain-rate dependent effects in composite materials, can be assigned to more recent CDM composite material models such as [13-15]. The latter models are highly advanced in capturing various continuously distributed static intra-lamina and inter-lamina damage mechanisms (e.g. fiber breakage within the yarns, fiber/ matrix de-bonding, diffuse delamination/inter-lamina separation etc.) as well as in accounting for discrete damage modes (e.g., transverse micro-cracking). Nevertheless, they fail to include the effect of rate dependency in composite materials and, hence, are not considered reliable for modeling the behavior of these materials under high strain rate loading conditions.

High strain rate and high pressure loading conditions generally occur in the impact area when a composite material is subjected to high velocity ballistic impact. Previous studies have shown that certain composite materials subjected to high rate loadings, such as blast and ballistic impact, exhibit significant strain rate sensitivity of both their stiffness and strength. Experimental characterization of the mechanical behavior of composite materials under high strain rate conditions has been reported in literature [16,17]. It has been shown that some protective materials such as woven glass and aramid composites exhibit significant rate sensitivity $[18,19]$.

To enhance the modeling capability of the progressive failure behavior of composite laminates due to transverse impact, a ratedependent composite lamina model based on the 3D stress field has been developed and reported herein. The model takes into account rate dependency of the composite-material response and can be used to accurately represent the aforementioned experimentally observed strain-rate effects. In this model, damageinitiation criteria have been developed for all major fiber failure (tensile, compressive, punch shear and crush loading) and matrix failure (in-plane shear and through the thickness delamination) modes. These are supplemented with the corresponding continuum damage-mechanics evolution laws/equations which characterize damage progression and the associated decrease in material stiffness.

The model has been implemented into explicit dynamic codes such as LS-DYNA as a user-defined subroutine. This material model can be used to effectively simulate fiber failure, matrix damage, and delamination behavior under different closure/loading conditions of the internal delaminated surfaces/cracks (e.g., crack-face opening, closure and sliding). Furthermore, this progressive failure modeling approach enables the prediction of delamination when locations of delamination sites cannot be anticipated; i.e., locations of potential delamination initiation are calculated without a-priori definition of an interlaminar crack surfaces. This material model has been successfully utilized previously by the author to characterize the impact damage in composite structures for a wide range of impact problems [1-4].

The organization of the paper is as follows: A brief account of the key features/relations of the present material model is provided in Section 2. Determination of the material parameters required by the model is given in Section 3, while the validation of the ballistic modeling capacity is provided in Section 4. The conclusions resulting from the present study are summarized in Section 5.

\section{Composite progressive failure model}

The ballistic material model for composite laminates reported herein considers the contribution of 3D strain state to damage initiation within plain weave fabric layers and provides an improved treatment of damage evolution (progressive failure). As will be shown later, the model can be used to effectively account for both damage/failure of the fiber reinforcements and the matrix under high strain-rate and high pressure ballistic impact conditions.

Strength-based failure criteria are commonly used with the finite element method to predict failure events in composites structures. A large number of continuum-based criteria have been derived to relate internal stresses and experimentally measured material strengths to the onset of failure. A general tensor polynomial criterion was proposed by Tsai and Wu [20] for failure of brittle unidirectional fiber composites. Hashin [21] pointed out the need of establishing failure criteria based on failure modes due to the fact that a unidirectional fiber composite consists of strong and stiff fibers and comparatively weak and compliant matrix. For these two very dissimilar phases, he proposed four different failure criteria relating to tensile and compressive failure of fibers and matrix for a unidirectional composite layer.

Over the last two decades, several researchers have proposed modifications to Hashin criteria to improve its prediction capabilities. Hashin failure criteria were modified to include the effect of transverse compressive normal stress on the matrix shear strength by Sun, et al. [22]. The application of the Mohr-Coulomb (M-C) criterion to transverse compression under combined transverse normal and axial shear stresses was studied by Chatterjee [23]. Using a simple modification to account for the difference between the transverse and axial shear strengths, he was able to obtain good correlation of matrix failure with experimental data of compression tests of angle ply as well as off-axis unidirectional specimens. The $\mathrm{M}-\mathrm{C}$ criterion was also used to include the effect of compression on the shear strengths of transverse matrix failure by Puck and Schurmanner [24] and Davila and Camanho [25]. In general, the use of $\mathrm{M}-\mathrm{C}$ for the transverse matrix failure has improved the accuracy over the Hashin matrix failure criterion. However, the effect of transverse normal stresses on the fiber failure also needs to be considered for accurately predicting the composite ballistic behavior.

The proposed failure model has been established by generalizing Hashin failure criteria [21] to a unidirectional composite lamina to account for 3D stress effects and to include the effects of high strain rate and high pressure on composite failure resulting from a wide range of ballistic/blast loading conditions. The unidirectional model has then been extended to a plain weave lamina. The Mohr-Coulomb $(\mathrm{M}-\mathrm{C})$ criterion has also been generalized for modeling the through the thickness fiber/matrix failure of a composite lamina where fracture under compression is very different from the fracture under tension.

\subsection{Damage-initiation/progression functions}

The unidirectional and fabric layer damage-initiation/ progression criteria developed in the present work are expressed in terms of ply-level engineering strains $\left(\varepsilon_{\mathrm{x}}, \varepsilon_{\mathrm{y}}, \varepsilon_{\mathrm{z}}, \varepsilon_{\mathrm{xy}}, \varepsilon_{\mathrm{yz}}, \varepsilon_{\mathrm{zx}}\right)$ with $\mathrm{x}, \mathrm{y}$ and $z$ denoting the in-plane fill, in-plane warp and out-of-plane directions, respectively. Note that for the unidirectional model, $x$, $\mathrm{y}$ and $\mathrm{z}$ denote the fiber, in-plane transverse and out-of-plane directions, respectively, while for the fabric model, $\mathrm{x}, \mathrm{y}$ and $\mathrm{z}$ denote the in-plane fill, in-plane warp and out-of-plane directions, respectively. The associated Young's and shear moduli are $\left(E_{\mathrm{x}}, E_{\mathrm{y}}, E_{\mathrm{z}}, G_{\mathrm{xy}}, G_{\mathrm{yz}}, G_{\mathrm{zx}}\right)$.

\subsubsection{Unidirectional lamina damage functions}

Three fiber damage mechanisms are considered: (a) damage under combined uniaxial tension and transverse shear; (b) damage under uniaxial compression; and (c) damage under transverse compressive loading. Matrix mode failures must occur without fiber failure, and hence they will be on planes parallel to fibers. Two 
matrix damage mechanisms are considered: (d) damage plane perpendicular to the layer plane under in-plane tensile and shear stresses; and (e) damage plane parallel to the layer plane (delamination) due to through-the-thickness tensile and shear stresses.

Uniaxial tension/Transverse shear

$f_{1}-r_{1}^{2}=\left(\frac{E_{\mathrm{x}}\left\langle\varepsilon_{\mathrm{x}}\right\rangle}{S_{\mathrm{xT}}}\right)^{2}+\frac{G_{\mathrm{xy}}^{2} \varepsilon_{\mathrm{xy}}^{2}+G_{\mathrm{xz}}^{2} \varepsilon_{\mathrm{xz}}^{2}}{S_{\mathrm{FS}}^{2}}-r_{1}^{2}=0$

Uniaxial Compression

$$
\begin{aligned}
f_{2}-r_{2}^{2} & =\left(\frac{E_{\mathrm{x}}\left\langle\varepsilon_{\mathrm{x}}^{\prime}\right\rangle}{S_{\mathrm{xC}}}\right)^{2}-r_{2}^{2}=0 \\
\varepsilon_{\mathrm{x}}^{\prime} & =\max \left\{-\varepsilon_{\mathrm{x}}-\left\langle-\varepsilon_{\mathrm{y}}\right\rangle \frac{E_{\mathrm{y}}}{E_{\mathrm{x}}},-\varepsilon_{\mathrm{x}}-\left\langle-\varepsilon_{\mathrm{z}}\right\rangle \frac{E_{\mathrm{z}}}{E_{\mathrm{x}}}\right\}
\end{aligned}
$$

Transverse Compression

$$
f_{3}-r_{3}^{2}=\left(\frac{E_{\mathrm{y}}\left\langle-\varepsilon_{\mathrm{y}}\right\rangle}{S_{\mathrm{FC}}}\right)^{2}+\left(\frac{E_{\mathrm{z}}\left\langle-\varepsilon_{\mathrm{z}}\right\rangle}{S_{\mathrm{FC}}}\right)^{2}-r_{3}^{2}=0
$$

where \langle\rangle are Macaulay brackets, $S_{\mathrm{xT}}$ and $S_{\mathrm{xC}}$ are the axial tensile and compressive strengths, respectively, and $S_{\mathrm{FS}}$ and $S_{\mathrm{FC}}$ are the fibershear controlled layer shear strength and crush failure strength, respectively. The damage thresholds, $r_{i} i=1,2,3$, which are set to 1 for the initial damage-free material. The individual failure criterion is then used to determine the onset of the associated fiber damage mode when the straining condition provides $f_{1}=1, f_{2}=1$ or $f_{3}=1$.

In Eq. (1), the unidirectional fiber tensile/shear damage is given by the quadratic interaction between the associated axial and through the thickness shear strains. This fiber failure is a generalization of the criterion of Hashin for a unidirectional layer. It is, however, important to note that the fiber shear failure, which is commonly observed under ballistic loading conditions, is governed by the layer (punch) shear strength $\left(S_{\mathrm{FS}}\right)$ and this mode of fiber failure was not covered by the original Hashin's model [21].

In Eq. (2), it is assumed that the in-plane compressive damage in the axial fiber directions is given by the maximum strain criterion, when $\varepsilon_{\mathrm{X}}$ is compressive. Note that the effect of transverse compressive strains on the in-plane compressive damage is taken into account.

When a composite material is subjected to transverse impact by a projectile, high compressive stresses will generally occur in the impact area with high shear stresses in the surrounding area between the projectile and the target material. While the fiber shear punch damage due to the high shear stresses can be accounted for by Eq. (1), the crush damage due to the high through the thickness compressive stresses is modeled using the criterion of Eq. (3).

\section{Perpendicular Matrix Damage}

$$
f_{4}-r_{4}^{2}=\left\{\left(\frac{E_{\mathrm{y}}\left\langle\varepsilon_{\mathrm{y}}\right\rangle}{S_{\mathrm{yUT}}}\right)^{2}+\left[\frac{G_{\mathrm{yz}} \varepsilon_{\mathrm{yz}}}{S_{\mathrm{yz} 0}+S_{\mathrm{ySR}}}\right]^{2}+\left[\frac{G_{\mathrm{xy}} \varepsilon_{\mathrm{xy}}}{S_{\mathrm{xy} 0}+S_{\mathrm{ySR}}}\right]^{2}\right\}-r_{4}^{2}=0
$$

Parallel Matric Damage (Delamination)

$$
f_{5}-r_{5}^{2}=S^{2}\left\{\left(\frac{E_{\mathrm{z}}\left\langle\varepsilon_{\mathrm{z}}\right\rangle}{S_{\mathrm{zUT}}}\right)^{2}+\left[\frac{G_{\mathrm{yz}} \varepsilon_{\mathrm{yz}}}{S_{\mathrm{yz} 0}+S_{\mathrm{zSR}}}\right]^{2}+\left[\frac{G_{\mathrm{xz}} \varepsilon_{\mathrm{xz}}}{S_{\mathrm{xz} 0}+S_{\mathrm{zSR}}}\right]^{2}\right\}-r_{5}^{2}=0
$$

where $r_{4}$ and $r_{5}$ are the damage thresholds for modes 4 and 5, respectively; $S_{\mathrm{yut}}$ and $S_{\mathrm{zUT}}$ are the transverse tensile strengths in the y and $z$ directions, respectively; and $S_{\mathrm{xy} 0}, S_{\mathrm{yz} 0}$ and $S_{\mathrm{xz} 0}$ are the shear strengths corresponding to the tensile modes in the associated directions, i.e. $\varepsilon_{\mathrm{y}} \geq 0$ or $\varepsilon_{\mathrm{z}} \geq 0$. Under compressive transverse strain, $\varepsilon_{\mathrm{y}}<0$ or $\varepsilon_{\mathrm{z}}<0$, the internal surfaces induced by matrix cracking are considered to be in full contact, and the damage strengths are assumed to be dependent on the associated compressive normal strain $\varepsilon_{\mathrm{y}}$ or $\varepsilon_{\mathrm{z}}$ similar to the Coulomb-Mohr theory, i.e.,

$S_{\mathrm{ySR}}=E_{\mathrm{y}} \tan \varphi_{\mathrm{U}}\left\langle-\varepsilon_{\mathrm{y}}\right\rangle$

$S_{\mathrm{ZSR}}=E_{\mathrm{Z}} \tan \varphi_{\mathrm{U}}\left\langle-\varepsilon_{\mathrm{z}}\right\rangle$

where $\varphi_{\mathrm{U}}$ is the Coulomb's friction angle.

While the damage surface due to Eq. (4) is perpendicular to the composite layer plane and is associated with transverse matrix cracking, the damage surface due to Eq. (5), which is the quadratic interaction between the thickness stresses, is parallel to the composite layer plane and is associated with inter-layer separation/ delamination. Note that a scale value $S$ is introduced into Eq. (5) to account for the stress concentration factor at the delamination front. During numerical simulations, $S$ value greater than 1.0 is assigned only to the composite laminate regions adjacent to the delamination front(s). No stress concentration effects are considered in the remainder of the composite laminate and $\mathrm{S}$ is set to 1.0.

In order to identify the delamination front elements, an array of elements surrounding the current active element is passed into the material subroutine from the main program of LS-DYNA. If the onset of delamination is computed in the active element during the current loading step, those surrounding elements, which are in the same composite layer plane but are not yet delaminated, are identified as the delamination front elements by flagging a history variable associated with each of those elements for assigning the $S$ value in the later loading steps. When an appropriate value for the scale factor $S$ is selected, this non-local approach was found to provide better correlation of delamination area with experiments. Such optimal value of the scale factor can be determined by fitting the analytical prediction to experimental data for the delamination area.

The damage criteria $f_{i}-r_{i}^{2}=0, i=1, \ldots, 5$, given in Eqs. (1)-(5) provide the damage initiation/progression surfaces in strain space. For the undamaged state, $r_{i}$ are set to 1 , and, thus, the material remains in the initial undamaged state as long as $f_{i}-1 \leq 0$, for each $i(i=1, \ldots, 5)$. The damage evolution laws introduced in the next section are used to model the damage progression behavior.

\subsubsection{Plain weave fabric lamina damage functions}

Similar to the unidirectional model, five fiber damage mechanisms are considered: (a) damage under combined uniaxial tension and transverse shear, fill and warp fibers are treated separately; (b) damage under uniaxial compression, fill and warp fibers are considered separately; and (c) damage under transverse compressive loading, no distinction between fill and warp fibers is made. Two matrix damage mechanisms are also considered: (d) damage under in-plane shear loading; and (e) delamination due to through-the-thickness tensile and shear stresses. The plain weave model was reported in Ref. [1] and is summarized as follows for the sake of completeness.

First, the fiber failure criteria of Hashin for a unidirectional layer are generalized to characterize the fiber damage in terms of strain components for a plain weave layer. The fill and warp fiber tensile/ shear damage are given by the quadratic interaction between the associated axial and through the thickness shear strains, i.e., 
$f_{6}-r_{6}^{2}=\left(\frac{E_{\mathrm{x}}\left\langle\varepsilon_{\mathrm{X}}\right\rangle}{S_{\mathrm{xT}}}\right)^{2}+\left(\frac{G_{\mathrm{Xz}} \varepsilon_{\mathrm{Xz}}}{S_{\mathrm{XFS}}}\right)^{2}-r_{6}^{2}=0$

$f_{7}-r_{7}^{2}=\left(\frac{E_{\mathrm{y}}\left\langle\varepsilon_{\mathrm{y}}\right\rangle}{S_{\mathrm{yT}}}\right)^{2}+\left(\frac{G_{\mathrm{yz}} \varepsilon_{\mathrm{yz}}}{S_{\mathrm{yFS}}}\right)^{2}-r_{7}^{2}=0$

where $S_{\mathrm{xT}}$ and $S_{\mathrm{yT}}$ are the axial tensile strengths in the fill and warp directions, respectively, and $S_{\mathrm{xFS}}$ and $S_{\mathrm{yFS}}$ are the layer shear strengths due to fiber shear failure in the fill and warp directions. These failure criteria are applicable when the associated $\varepsilon_{\mathrm{x}}$ or $\varepsilon_{\mathrm{y}}$ is positive. The damage thresholds $r_{6}$ and $r_{7}$ are equal to 1 without damage.

When $\varepsilon_{\mathrm{x}}$ or $\varepsilon_{\mathrm{y}}$ is compressive, it is assumed that the in-plane compressive damage in the fill and warp directions are given by the maximum strain criterion, i.e.,

$f_{8}-r_{8}^{2}=\left(\frac{E_{\mathrm{X}}\left\langle\varepsilon_{\mathrm{x}}^{\prime}\right\rangle}{S_{\mathrm{xC}}}\right)^{2}-r_{8}^{2}=0, \quad \varepsilon_{\mathrm{x}}^{\prime}=-\varepsilon_{\mathrm{x}}-\left\langle-\varepsilon_{\mathrm{z}}\right\rangle \frac{E_{\mathrm{z}}}{E_{\mathrm{X}}}$

$f_{9}-r_{9}^{2}=\left(\frac{E_{\mathrm{y}}\left\langle\varepsilon_{\mathrm{y}}^{\prime}\right\rangle}{S_{\mathrm{yc}}}\right)^{2}-r_{9}^{2}=0, \quad \varepsilon_{\mathrm{y}}^{\prime}=-\varepsilon_{\mathrm{y}}-\left\langle-\varepsilon_{\mathrm{z}}\right\rangle \frac{E_{\mathrm{z}}}{E_{\mathrm{y}}}$

where $S_{\mathrm{xc}}$ and $S_{\mathrm{yc}}$ are the axial compressive strengths in the fill and warp directions, respectively, and $r_{8}$ and $r_{9}$ are the corresponding damage thresholds.

The crush damage due to the high through the thickness compressive pressure is modeled using the following criterion: failure. This through the thickness matrix failure criterion is assumed to have the following form:

$f_{12}-r_{12}^{2}=S^{2}\left\{\left(\frac{E_{\mathrm{z}}\left\langle\varepsilon_{\mathrm{z}}\right\rangle}{S_{\mathrm{zT}}}\right)^{2}+\left[\frac{G_{\mathrm{yz}} \varepsilon_{\mathrm{yz}}}{S_{\mathrm{yz} 0}+S_{\mathrm{SR}}}\right]^{2}+\left[\frac{G_{\mathrm{xz}} \varepsilon_{\mathrm{xz}}}{S_{\mathrm{xz} 0}+S_{\mathrm{SR}}}\right]^{2}\right\}-r_{12}^{2}=0$

where $r_{12}$ is the damage threshold, $S_{\mathrm{zT}}$ is the through the thickness tensile strength, and $S_{\mathrm{yz} 0}$ and $S_{\mathrm{xzo}}$ are the shear strengths for tensile $\varepsilon_{\mathrm{z}}$. The damage surface due to Eq. (12) is parallel to the composite layering plane. Under compressive through the thickness strain, $\varepsilon_{\mathrm{c}}<0$, the damaged surface (delamination) is considered to be "closed", and the damage strengths are assumed to depend on the compressive normal strain $\varepsilon_{\mathrm{c}}$ similar to the Coulomb-Mohr theory, i.e.,

$S_{\mathrm{SR}}=E_{\mathrm{z}} \tan \varphi\left\langle-\varepsilon_{\mathrm{z}}\right\rangle$

where $\varphi$ is the Coulomb's friction angle. Similar to the unidirectional model, a scale factor $S$ is introduced to provide better correlation of delamination area with experiments. The scale factor $\mathrm{S}$ can be determined by fitting the analytical prediction to experimental data for the delamination area.

\subsection{Damage evolution laws}

To quantify the extent of damage-induced stiffness loss, six damage variables $\varpi_{j}$ with $j=1, \ldots 6$, are introduced, one for each of the six moduli mentioned earlier. The compliance matrix $S$ is related to the damage variables as in Ref. [10]:

$$
\left[\mathrm{S}^{*}\right]=\left[\begin{array}{cccccc}
\frac{1}{\left(1-\varpi_{1}\right) \mathrm{E}_{\mathrm{x}}} & \frac{-\nu_{\mathrm{yx}}}{\mathrm{E}_{\mathrm{y}}} & \frac{-\nu_{\mathrm{zx}}}{\mathrm{E}_{\mathrm{z}}} & 0 & 0 & 0 \\
\frac{-\nu_{\mathrm{xy}}}{\mathrm{E}_{\mathrm{x}}} & \frac{1}{\left(1-\varpi_{2}\right) \mathrm{E}_{\mathrm{y}}} & \frac{-\nu_{\mathrm{zy}}}{\mathrm{E}_{\mathrm{z}}} & 0 & 0 & 0 \\
\frac{-\nu_{\mathrm{xz}}}{\mathrm{E}_{\mathrm{x}}} & \frac{-\nu_{\mathrm{yz}}}{\mathrm{E}_{\mathrm{y}}} & \frac{1}{\left(1-\varpi_{3}\right) \mathrm{E}_{\mathrm{z}}} & 0 & 0 & 0 \\
0 & 0 & 0 & \frac{1}{\left(1-\varpi_{4}\right) \mathrm{G}_{\mathrm{xy}}} & 0 & 0 \\
0 & 0 & 0 & 0 & \frac{1}{\left(1-\varpi_{5}\right) \mathrm{G}_{\mathrm{yz}}} & 0 \\
0 & 0 & 0 & 0 & 0 & \frac{1}{\left(1-\varpi_{6}\right) \mathrm{G}_{\mathrm{zx}}}
\end{array}\right]
$$

$f_{10}-r_{10}^{2}=\left(\frac{E_{\mathrm{Z}}\left\langle-\varepsilon_{\mathrm{Z}}\right\rangle}{S_{\mathrm{FC}}}\right)^{2}-r_{10}^{2}=0$

where $S_{\mathrm{FC}}$ is the fiber crush strengths and $r_{10}$ is the associated damage threshold.

A plain weave layer can be damaged under in-plane shear stressing without occurrence of fiber breakage. This in-plane matrix damage mode is given by

$f_{11}-r_{11}^{2}=\left[\frac{G_{\mathrm{xy}} \varepsilon_{\mathrm{xy}}}{S_{\mathrm{xy}}}\right]^{2}-r_{11}^{2}=0$

where $S_{\mathrm{xy}}$ is the layer shear strength due to matrix shear failure and $r_{11}$ is the damage threshold.

Another failure mode, which is due to the quadratic interaction between the thickness strains, is expected to be mainly a matrix
The stiffness matrix $\mathrm{C}$ is obtained by inverting the compliance matrix, $[C]=\left[S^{*}\right]^{-1}$.

As suggested in Matzenmiller et al. [10], the growth rate of damage variables $\dot{\varpi}_{j}$, is defined by the following type of evolution law:

$\dot{\varpi}_{j}=\sum_{i} \dot{\phi}_{i} q_{j i}$

where the scalar functions $\dot{\phi}_{i}(i=1, \ldots, 12)$ define the growth rate of damage mode, $i$, and the binary vector-valued functions $q_{j i}$ $(j=1, \ldots 6, i=1, \ldots, 12)$ provide the coupling between the individual damage variables, $\varpi_{j}$, and one of the previously defined seven damage modes (each characterized by its damage-initiation function $f_{i}$ ). 


\subsubsection{Derivation of $\dot{\phi}_{i}$}

As described previously, the damage criteria $f_{i}-r_{i}^{2}=0$ of Eqs. (1) -(5) or (8)-(12) provide the damage surfaces in strain space. The growth rate of damage type $i, \dot{\phi}_{i}$, will be non-zero when the strain path crosses the corresponding updated damage surface $f_{i}-r_{i}^{2}=0$ and the associated strain-vector increment has a positive component along the outward normal to the damage surface, i.e., when $\sum_{k}\left(\partial f_{i} / \partial \varepsilon_{k}\right) \dot{\varepsilon}_{k}>0$, where $k(=1, \ldots, 6)$ is used to denote six components of the strain vector. Combined with a damage growth function $\gamma_{i}\left(\varepsilon_{k}, \varpi_{j}\right), \dot{\phi}_{i}$ is assumed to have the form

$\dot{\phi}_{i}=\sum_{k} \gamma_{i} \frac{\partial f_{i}}{\partial \varepsilon_{k}} \dot{\varepsilon}_{k}$

Choosing

$\gamma_{i}=\frac{1}{2}\left(1-\phi_{i}\right) f_{i}^{\frac{m}{2}-1}$

and noting that

$\sum_{k} \frac{\partial f_{i}}{\partial \varepsilon_{k}} \dot{\varepsilon}_{k}=\dot{f}_{i}$

for the quadratic functions of Eqs. (1)-(5) or (8)-(12), leads to

$\dot{\phi}_{i}=\frac{1}{2}\left(1-\phi_{i}\right) f_{i}^{\frac{m}{2}-1} \dot{f}_{i}($ no summation over $i)$

where $\phi_{i}$ is a variable representing the extent of mode-i damage, and $m$ is a material constant that quantifies sensitivity of the material stiffness to the extent of damage. To summarize, Eq. (19) governs the rate of progression of different damage modes and, in turn, the extent of stiffness loss as a function of damage with multiple damage modes. As described in Ref. [10], the $\gamma_{i}$ of Eq. (17) is chosen to ensure that a Weibull distribution for damage flaw accumulation is realized for the softening behavior under the unidirectional straining condition.

\subsubsection{Derivation of $q_{j i}$}

For the fiber tensile/shear and compressive damage of modes of 6-9 defined in the fabric model, the damage coupling vector $q_{6 i}, q_{7 i}$, $q_{8 i}$ and $q_{9 i}$ are chosen such that the fiber damage in either the fill and warp direction results in stiffness reduction in the loading direction and in the related shear directions. For the fabric fiber crush damage of mode 10 , the damage coupling vector $q_{10 i}$ is chosen such that all the stiffness values are reduced as an element is failed under the crush mode. For the fabric in-plane matrix shear failure of mode 11, the stiffness reduction due to $q_{11 i}$ is limited to in-plane shear modulus, while the through-the-thickness matrix damage (delamination) of mode 12 , the coupling vector $q_{12 i}$ is chosen for the through thickness tensile modulus and shear moduli. The damage coupling matrix $q_{i j}$ for the unidirectional model can be established accordingly. Consequently, the damage coupling functions $q_{j i}$ for the unidirectional and fabric models, respectively, are then

$$
\begin{aligned}
& {[q]=\left[q_{\text {uni }}, q_{\text {fabric }}\right]} \\
& {\left[q_{\text {uni }}\right]=\left[\begin{array}{lllll}
1 & 1 & 1 & 0 & 0 \\
0 & 0 & 1 & 1 & 0 \\
0 & 0 & 1 & 0 & 1 \\
1 & 1 & 1 & 1 & 0 \\
0 & 0 & 1 & 1 & 1 \\
1 & 1 & 1 & 0 & 1
\end{array}\right],\left[q_{\text {fabric }}\right]=\left[\begin{array}{lllllll}
1 & 0 & 1 & 0 & 1 & 0 & 0 \\
0 & 1 & 0 & 1 & 1 & 0 & 0 \\
0 & 0 & 0 & 0 & 1 & 0 & 1 \\
1 & 1 & 1 & 1 & 1 & 1 & 0 \\
0 & 1 & 0 & 1 & 1 & 0 & 1 \\
1 & 0 & 1 & 0 & 1 & 0 & 1
\end{array}\right]}
\end{aligned}
$$

Through Eq. (15), the above function $q_{j i}$ relates the individual damage variables $\varpi_{j}$ to the various damage modes provided by the damage functions of the fabric models.

\subsubsection{Derivation of $\varpi_{j}$}

Utilizing the damage coupling functions of Eq. (20) and the growth function of Eq. (19), a damage variable $\varpi_{j}$ can be obtained from Eq. (15) for an individual failure mode $i$ as

$\varpi_{j}=1-e^{\frac{1}{m}\left(1-r_{i}^{m}\right)}, \quad r_{i} \geq 1$

Note that the damage thresholds $r_{i}$ given in the damage-initiation criteria of Eqs. (1)-(5) and (8)-(12) are continuously increasing functions with increasing damage. The damage thresholds have an initial value of one, which results in a zero value for the associated damage variable $\varpi_{j}$, in accordance with Eq. (21). This condition defines an initial damage-free elastic region bounded by the damage functions in strain space. The nonlinear material response is modeled by enabling the damage surfaces to expand and the damage threshold $r_{i}$ to increase as a result of increase in damage of type $i$. This, in turn, causes an increase in the associated damage variable(s) $\varpi_{j}$ and a decrease in material stiffness. Reduction in material stiffness associated with an increase in damage variables $\varpi_{j}$ is governed by Eq. (15). In other words, within the strain space bounded by the damage surface material response remains elastic while the material stiffness is governed by the extent of damage. When fiber tensile/shear damage of a fabric layer is predicted in a layer by Eq. (8), the load carrying capacity of that layer in the associated direction is reduced to zero according to damage variable Eq. (21). On the other hand, when fiber compressive damage is predicted in a fabric layer by Eq. (9), the layer is assumed to retain a residual strength in the damaged direction. For the fill and warp fibers, the residual strengths are denoted as $S_{\mathrm{xCR}}$ and $S_{\mathrm{yCR}}$, respectively. To account for this residual stiffness/strength effect, the damage variables of Eq. (21) for the compressive failure modes have been modified in the fill and warp directions, as

$$
\begin{aligned}
& \varpi_{j}=\left(1-e^{\frac{1}{m}\left(1-r_{i}^{m}\right)}\right)\left(1-\eta_{i}\right), \quad i=3 \text { or } 4 \\
& \left\{\begin{array}{l}
\eta_{3} \\
\eta_{4}
\end{array}\right\}=\left\{\begin{array}{l}
\frac{S_{\mathrm{xCR}}}{E_{\mathrm{x}} \varepsilon_{\mathrm{x}}^{\prime}} \\
\frac{S_{\mathrm{yCR}}}{E_{\mathrm{y}} \varepsilon_{\mathrm{y}}^{\prime}}
\end{array}\right\}
\end{aligned}
$$

For through the thickness matrix (delamination) failure in a fabric layer given by Eq. (12), the in-plane load carrying capacity within the element is assumed to be elastic (i.e., no in-plane damage). The load carrying behavior in the through the thickness direction is assumed to depend on the opening or closing of the internal delaminated surfaces. For tensile loading, $\varepsilon_{z}>0$, the through-the thickness-stress components are softened and ultimately reduced to zero due to the damage criteria described above. For compressive loading, $\varepsilon_{z}<0$, the internal delaminated surfaces are considered to be closed, and thus, $\sigma_{\mathrm{z}}$ is assumed to be elastic, while $\tau_{\mathrm{yz}}$ and $\tau_{\mathrm{zx}}$ are allowed to reduce to a sliding friction stress of Eq. (13). Accordingly, for the through-the-thickness matrix failure of mode 12 under compressive loading, the damage variable Eq. (21) is further modified to account for the residual sliding strength $\mathrm{S}_{\mathrm{SR}}$ of the form

$\left\{\begin{array}{l}\varpi_{5} \\ \varpi_{6}\end{array}\right\}=\left(1-e^{\frac{1}{m}\left(1-r_{7}^{m}\right)}\right)\left(1-\frac{S_{\mathrm{SR}}}{\left[\left(G_{\mathrm{yz}} \varepsilon_{\mathrm{yz}}\right)^{2}+\left(G_{\mathrm{zx}} \varepsilon_{\mathrm{zx}}\right)^{2}\right]^{1 / 2}}\right)$ 
where the sliding strength is given by Eq. (13). Note that the modifications of $\omega_{j}$ for an unidirectional layer to account for the residual behavior can be carried out similar the procedure described above for a fabric layer.

\subsection{Typical stress-strain response and damage surface}

Fig. 1 shows typical axial tensile and compressive stress-strain curves obtained using the present progressive-damage composite-material model for a plain weave S2/Epoxy layer with a value of 4.0 assigned to the damage model parameter, $m$. Fig. 1(a) shows that, under monotonic loading, the model provides an initial damage-free elastic response up to the stress values of $586 \mathrm{MPa}$ (85 ksi) for tension and $345 \mathrm{MPa}$ (50 ksi) for compression. This is followed by a post damage-initiation material response characterized by continued softening. Note that the compressive stress reduces ultimately to a residual strength of $103 \mathrm{MPa}$ (15 ksi) and remains constant afterward. Fig. 1(b) shows stress-strain curves due to cyclic loading along the fill-fiber direction (direction $x$ ). It demonstrates the effect of the accumulated damage on the stressstrain response. Note that during unloading/reloading, the material is more compliant than the initial damage-free material. The associated reduced elastic modulus is equal to $\left(1-\varpi_{1}\right) E_{\mathrm{X}}$, where $\varpi_{1}$ is the updated damage parameter for the axial fiber damage mode.

Fig. 2 shows typical axial shear stress-strain curves obtained from the damage model. Shown in Fig. 2a are the shear stress-strain curves for $\tau_{\mathrm{zx}}$ with tensile through the thickness normal loads (opening delamination). Fig. $2 \mathrm{~b}$ shows the effect of the compressive through the thickness normal stress (closing delamination), $\sigma_{z}$ on the $\tau_{\mathrm{zx}}$ stress-strain response for a Coulomb's friction angle $\varphi=20^{\circ}$.

Fig. 3 shows the typical stress-strain curves of a unidirectional S2/Epoxy layer. It demonstrates the energy absorption capacity in the axial fiber direction is significantly higher than those associated with the fracture due to matrix damage resulted from the transverse tensile and in-plane shear loadings.

\subsection{Strain-rate dependent formulation}

The effect of strain rate on the mechanical response of composite laminates is modeled by making strength values appearing in Eqs. (1)-(5) and (8)-(12) and the six elastic moduli, strain-rate dependent quantities. Strength values are made strainrate dependent through the introduction of a scale factor as

$$
\begin{aligned}
&\left\{S_{\mathrm{RT}}\right\}=\left\{S_{0}\right\}\left(1+C_{1} \ln \frac{\{\dot{\bar{\varepsilon}}\}}{\dot{\varepsilon}_{0}}\right) \\
&\left\{S_{\mathrm{RT}}\right\}=\left\{\begin{array}{l}
S_{\mathrm{xT}} \\
S_{\mathrm{yT}} \\
S_{\mathrm{xC}} \\
S_{\mathrm{yC}} \\
S_{\mathrm{FC}} \\
S_{\mathrm{xFC}} \\
S_{\mathrm{yFS}}
\end{array}\right\}_{\mathrm{RT}},\left\{S_{0}\right\}=\left\{\begin{array}{l}
S_{\mathrm{xT}} \\
S_{\mathrm{yT}} \\
S_{\mathrm{xC}} \\
S_{\mathrm{yC}} \\
S_{\mathrm{FC}} \\
S_{\mathrm{xFC}} \\
S_{\mathrm{yFS}}
\end{array}\right\}_{0} \quad \text { and }\{\dot{\bar{\varepsilon}}\}=\left\{\begin{array}{l}
\left|\dot{\varepsilon}_{\mathrm{x}}\right| \\
\left|\dot{\varepsilon}_{\mathrm{y}}\right| \\
\left|\dot{\varepsilon}_{\mathrm{x}}\right| \\
\left|\dot{\varepsilon}_{\mathrm{y}}\right| \\
\left|\dot{\varepsilon}_{\mathrm{z}}\right| \\
\left|\dot{\varepsilon}_{\mathrm{zx}}\right| \\
\left|\dot{\varepsilon}_{\mathrm{zy}}\right|
\end{array}\right\}
\end{aligned}
$$

where $C_{1}$ is the strain rate constant, and $\left\{S_{0}\right\}$ are the strength values of $\left\{S_{\mathrm{RT}}\right\}$ at the reference strain rate $\dot{\varepsilon}_{0}$.

The strain-rate effect on the layer elastic moduli is modeled in an analogous fashion as:

$$
\begin{aligned}
& \left\{E_{\mathrm{RT}}\right\}=\left\{E_{0}\right\}\left(1+C_{2} \ln \frac{\{\dot{\bar{\varepsilon}}\}}{\dot{\varepsilon}_{0}}\right) \\
& \left\{E_{\mathrm{RT}}\right\}=\left\{\begin{array}{l}
E_{\mathrm{X}} \\
E_{\mathrm{y}} \\
E_{\mathrm{z}} \\
G_{\mathrm{xy}} \\
G_{\mathrm{yz}} \\
G_{\mathrm{zx}}
\end{array}\right\}_{\mathrm{RT}} \text { and }\left\{E_{0}\right\}=\left\{\begin{array}{l}
E_{\mathrm{X}} \\
E_{\mathrm{y}} \\
E_{\mathrm{z}} \\
G_{\mathrm{xy}} \\
G_{\mathrm{yz}} \\
G_{\mathrm{zx}}
\end{array}\right\}_{0}
\end{aligned}
$$

where $\left\{E_{0}\right\}$ are the moduli of $\left\{E_{\mathrm{RT}}\right\}$ at the reference strain rate $\dot{\varepsilon}_{0}$. The effect of strain rate on the axial stress-strain response is shown in Fig. 4 for $C_{1}=0.02$ and $C_{2}=0$.

\section{Material-model parameterization}

\subsection{In-plane strength and modulus strain-rate dependence parameters}

A literature survey has been conducted to identify the effect of strain-rate on the composite strength properties. Reviews of works and development in the area concerning the mechanical behavior of composite materials under high strain rate conditions are reported in Refs. [5,16,17 and 26]. In general, the experimental data indicates that composite failure strength is sensitive to the strain rate for glass/ epoxy plain weave composites and much less so for carbon.
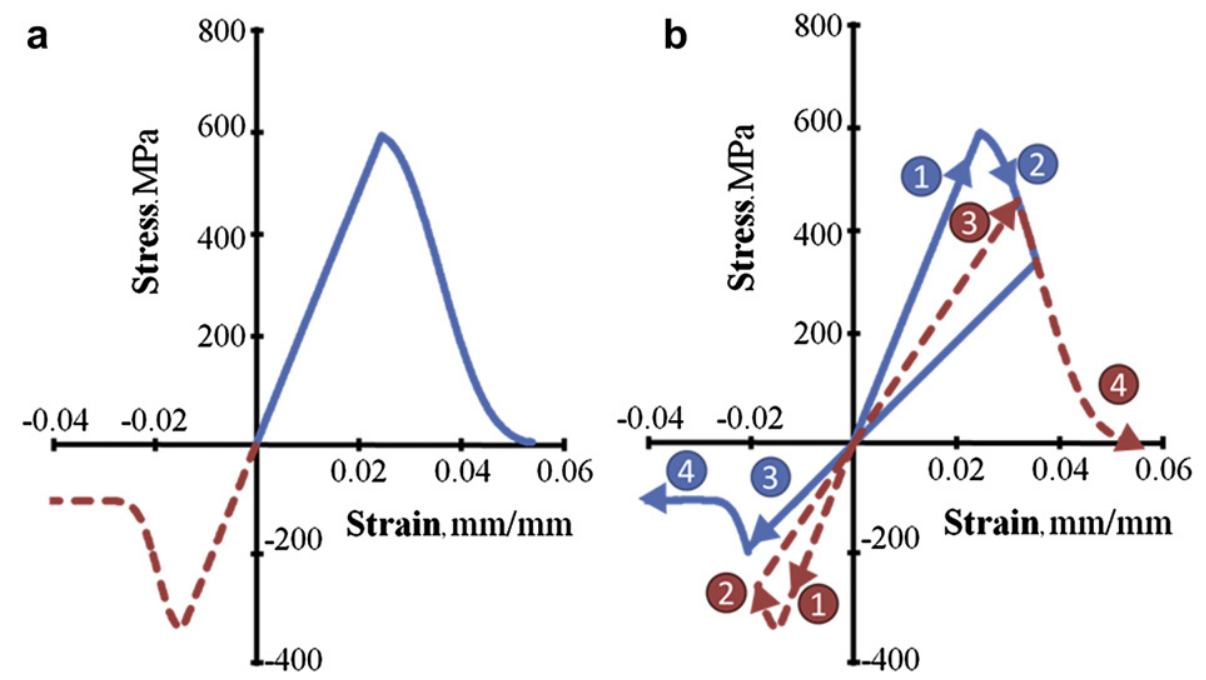

Fig. 1. Axial stress-strain curves for damage model under (a) Monotonic and (b) Cyclic loading conditions. 

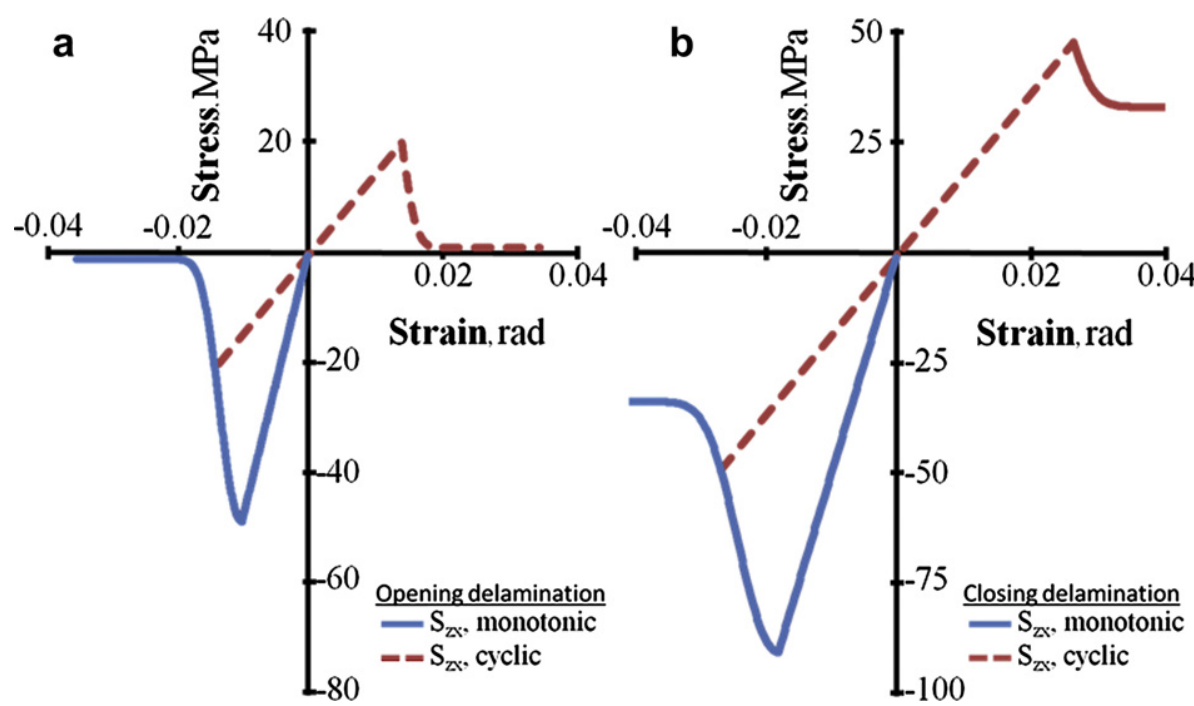

Fig. 2. Shear stress-strain curves for damage model under the effect of through the thickness normal load, (a) Opening delamination and (b) Closing delamination.

Various public-domain experimental data has been utilized to determine strength $\left(\left\{S_{0}\right\}\right.$ and $\left.C_{1}\right)$ and modulus $\left(\left\{E_{0}\right\}\right.$ and $\left.C_{2}\right)$ strainrate dependency parameters for various composite systems and reported in [2] and [3]. Typical strain-rate dependent tensile and shear punch data for a fine weave glass composite was obtained by Hopkinson Pressure Bar testing (HPBT) and reported in [27] and [18], respectively. It was shown in [2] that these tensile and shear punch stress-strain curves can be accurately represented by the material model using the proper rate-dependent modulus, strength and damage parameters.

Of particular interest in this study is the dynamic behavior of the S2-glass/Epoxy plain weave composite laminates. The dynamic compressive stress-stain data of HPBT was reported by Song et al. [28], and shows in Fig. 5. The plain weave laminate shows a moderate increase in modulus, strength, and strain to failure with increasing strain rate. Fig. 5 also shows the computed stress-strain curves using the proposed material model for strain-rates ranging from $1 / \mathrm{sec}$ to $10^{4} / \mathrm{sec}$. Note that the modeling results for the GFRP composite were obtained by using the rate-dependent modulus, strength and damage parameters of $C_{1}=0.03, C_{2}=0.03$ and $m=4$. It

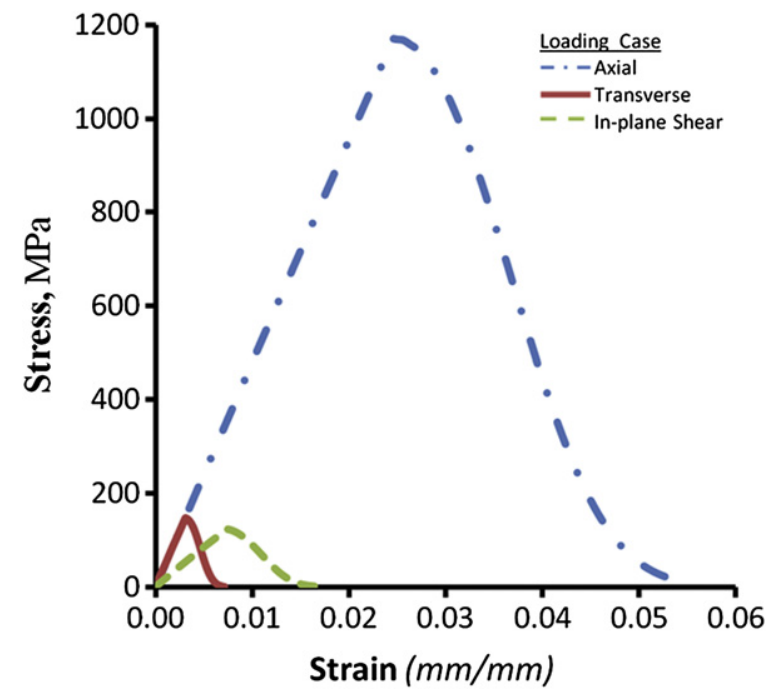

Fig. 3. Stress-strain curves of a unidirectional layer for axial tensile, transverse tensile and in-plane shear loads. is seen that the proposed material model can represent the overall rate-dependent nonlinear stress-strain response reasonably well.

It is important to note that in order to accurately account for the experimentally observed strain-rate dependency of the in-plane tensile and punch shear strengths over a wide strain-rate range multiple values of the strain rate constants $C_{1}$ and $C_{2}$ may be required. However, it should be recognized that under ballistic impact conditions, it is expected that the composite failure will mainly occur under relatively high strain rates, i.e., $\dot{\varepsilon} \geq 1 \mathrm{~s}^{-1}$. Therefore, for the correlation shown in Fig. 5, as well as the ballistic impact analysis reported later, the use of single values of $C_{1}$ and $C_{2}$ with a cut-off strain rate $\dot{\varepsilon}_{\mathrm{c}}$ is recommended. For the current S2glass/Epoxy plain weave laminate, it assumes that the strengths remain constant (rate independent) for strain rates below the cutoff threshold at $1.0 \mathrm{~s}^{-1}$.

\subsection{Crush compressive and punch-shear fiber strengths}

Typical ballistic impact tests as well as ballistic simulation studies have indicated that the fiber shear failure resulting from the

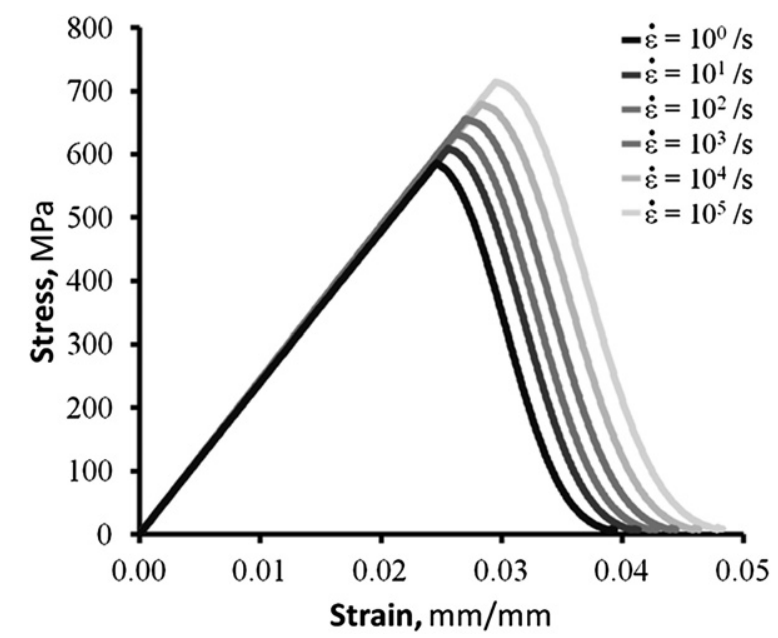

Fig. 4. Axial tensile stress-strain curves for damage model under various constant strain rate loading. 


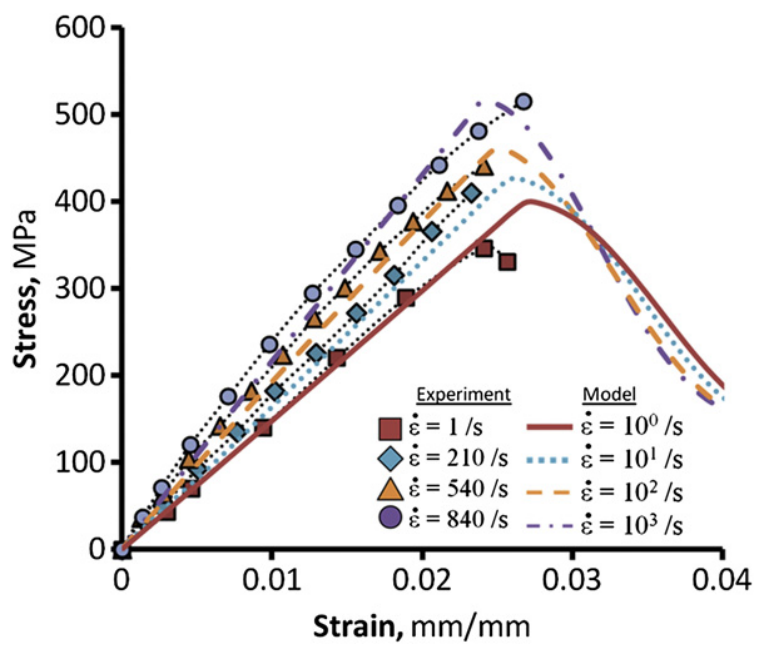

Fig. 5. Comparison of axial stress-strain response between modeling results and test data [28] for various constant strain-rates.

through-thickness impact loading has had an important effect on the ballistic capacity of composite laminates [1,2]. It is expected that during high-velocity impact, large normal stresses are created in the direction orthogonal to the layer surfaces and that these stresses may induce shear failure along weak material planes. In unidirectional composites such failure usually occurs without cutting the fibers and this matrix dominated shear strength is typically very low $[29,30]$. Collin [31] performed compression tests using cube-shaped thick unidirectional-composite specimens by loading in one of the transverse directions, but providing constraint in the axial fiber direction. As the specimen is allowed to expand in the unconstrained transverse direction, matrix dominated failure has been found to occur in the transverse direction. It was mentioned previously that such matrix shear failure under the influence of normal stress can be accurately modeled by taking into consideration the effect of transverse compression under combined transverse normal and axial shear stresses using $\mathrm{M}-\mathrm{C}$ criterion [23].

The effect of transverse normal stresses on the fiber failure has, however, drawn less attention. It is important to note that fiber failure under transverse compressive loading cannot be accurately predicted by the original Hashin failure model [21] since transverse shear mode of failure was not considered in the original Hashin failure model. In this work, the compressive loading is considered to contribute to both crush failure (Eq. (3) or (10)) and transverse shear failure (Eq. (1) or (8)) of the fibers. The required shear composite failure strengths for the fiber breakage due to the through-thickness compressive loading can be obtained from the laterally constrained compression test (LCCT) procedure.

The laterally constrained compression test procedure originally used by Collin [31] was extended to characterize the shear failure strength of fibers in both unidirectional and plain weave laminates. Fig. 6 shows the transversely constrained compression test fixture introduced by Collin. It is seen that one of the fiber directions of a plain weave composite specimen is arranged in the $x$ direction, the compressive load is applied in the through the thickness direction $z$ (perpendicular to the lamination planes) while the lateral constraint is provided to the other in-plane fiber direction $y$. Utilizing this LCCT, fiber shear failure is introduced as a result of the transverse compressive load. A failure surface cutting through the fibers with an inclined angle in the compressive loading direction typically results from such a compressive test.

By loading the specimen in the through-thickness direction and constraining laterally in one direction, failure must occur on certain (z)

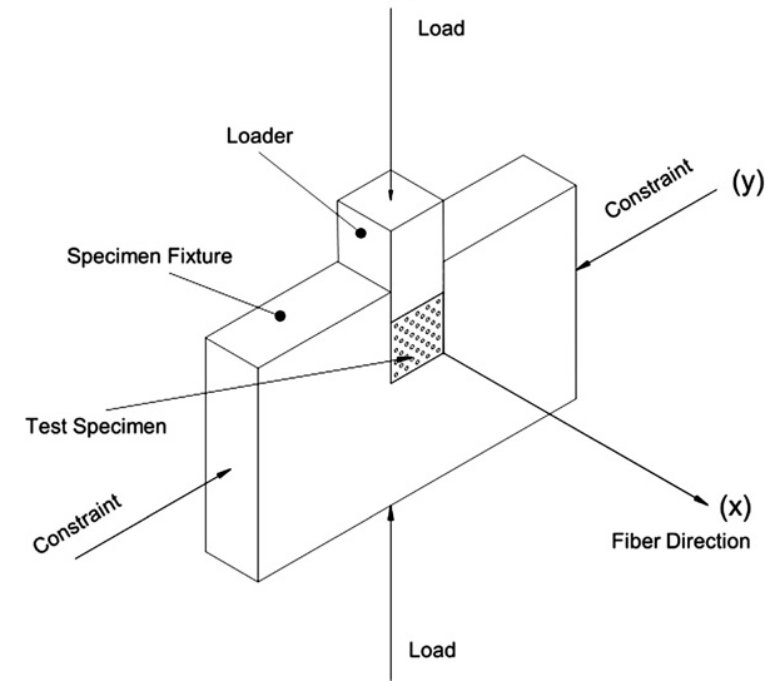

Fig. 6. Laterally constrained transverse compressive test fixture and unidirectional specimen.

preferred planes cutting the fibers. In particular, for homogeneous materials obeying Tresca or Mohr-Coulomb type strength criterion, failure will occur by sliding on planes perpendicular to the faces which are constrained (the plane making an angle $\theta$ to the throughthickness plane as shown in Fig. 7). In plain weave fiber reinforced composites, such failures are possible only after a shear type failure in the fibers occurs. In woven fabric composite with fibers running in two perpendicular directions, one set of fibers (which are more highly stressed) will likely fail in shear before the other. Fig. 6 shows the front view from the constrained side indicating shear failure cutting fibers in the unconstrained direction.

For the case of plain weave specimens with one of the warp $\left(0^{\circ}\right)$ or fill $\left(90^{\circ}\right)$ fiber direction coinciding with the unconstraint direction, the following stresses exist when the compressive stress on the specimen is $S_{\mathrm{FC}}$,

$$
\begin{aligned}
& S_{\mathrm{NFS}}=0.5 S_{\mathrm{FC}} \sin 2 \theta \\
& S_{\mathrm{N}}=S_{\mathrm{FC}} \cos ^{2} \theta
\end{aligned}
$$

where $S_{\mathrm{NFS}}$ and $S_{\mathrm{N}}$ are shear and compressive normal stresses, respectively, and $\theta$ is the angle of the shear sliding plane shown in Fig. 7. The above equations are obtained using the two principal stresses, i.e., compressive stress $S_{\mathrm{FC}}$ and zero. The other (intermediate compressive) principal stress (on planes parallel to the constrained faces) does not contribute to the stresses in Eq. (26).

The crush strength, $S_{\mathrm{FC}}$, for S-2 Glass/Epoxy composite was measured using cubes with sides of 0.5 inch and 0.75 inch. For each specimen size, both of the $0^{\circ}$ and $90^{\circ}$ plain weave composite

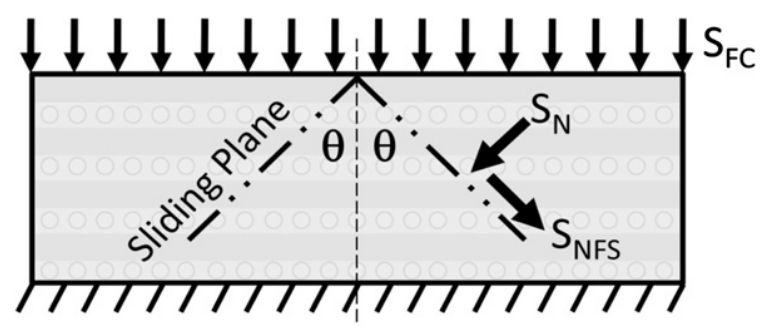

\section{Front View -0 or 90 orientation}

Fig. 7. Shear failure plane cutting fibers under transverse compression. 
orientations were tested. The volume fractions of fiber reinforcements in $0^{\circ}$ and $90^{\circ}$ directions govern the composite fiber shear strength and the crush strength. For the material tested, the amount of reinforcements in the two directions is nearly equal. The crush strengths for the two orientations for 0.75 inch cubes are similar. The average values for $0^{\circ}$ and $90^{\circ}$ orientations are $758 \mathrm{MPa}$ ( $110 \mathrm{ksi}$ ) and $745 \mathrm{MPa}(108 \mathrm{ksi})$, respectively. For 0.5 inch cubes, the average values for the two orientations differ by $6 \%$ with average values of $724 \mathrm{MPa}$ (105 ksi) and $683 \mathrm{MPa}$ (99 ksi). It may be noted that for smaller specimens the amount of fibers may be affected by the location of the machining planes with respect to the fiber yarns. Therefore, test data for 0.7 inch cubes appear to be more reliable and the value of the average of the $0^{\circ}$ and $90^{\circ}$ crush strengths $\left(S_{\mathrm{FC}}=751 \mathrm{MPa}(109 \mathrm{ksi})\right.$ ) was used to calculate the punch shear strength $S_{F S}$ using Eq. (26).

Before the value of the fiber punch shear strength $S_{\mathrm{FS}}$ can be calculated, one must determine the failure plane angle $\theta$. For plain weave composite-laminate architectures, the failure planes are often corrugated and exhibit a zigzag pattern. A typical fracture surface in plain-weave composite material specimens failed by shear of $0^{\circ}$ fibers is shown in Fig. 8. It appears that failure possibly initiates in some fiber yarns in the composite fiber shear failure mode, which is followed by very localized inter-yarn and/or interlayer de-bonding which offset the shear plane in subsequent layers. The failure planes are measured from the failed specimens and the value of $\theta$ lies between $40^{\circ}$ and $42^{\circ}$. Therefore, a value of $41^{\circ}$ was used to calculate $S_{\mathrm{FS}}=751 \mathrm{MPa}(109 \mathrm{ksi})$.

The fiber shear failure behavior of a plain weave layer is modeled by Eq. (8) where the required punch-shear strength values of $S_{\mathrm{xFS}}$ and $S_{\mathrm{yFS}}$ are the $S_{\mathrm{FS}}$ values obtained from the laterally constrained transverse compression tests in the $x$ and $y$ directions, respectively. The measured fiber shear strength allows us to construct the failure envelope associated with the through the thickness components $\left(\sigma_{\mathrm{z}}, \tau_{\mathrm{zx}}\right)$ for the tested S2/Epoxy plain weave layer shown in Fig. 9. The matrix strength failure envelope is governed by Eq. (12) for both the tensile and compressive through the thickness normal stress. The fiber shear strength is given by equation (8), while the crush strength is provided by equation (10). The residual strength of fractured material under shear stress is provided by the Coulomb-Mohr criterion of equation (7) with $S_{x z 0}$ set to zero where $\varphi=8^{\circ}$ as given in Ref. [1].

\section{Material-model additional parameterization and validation}

In this section, a series of ballistic impact computational analyses of composite laminates with projectiles is carried out and the results

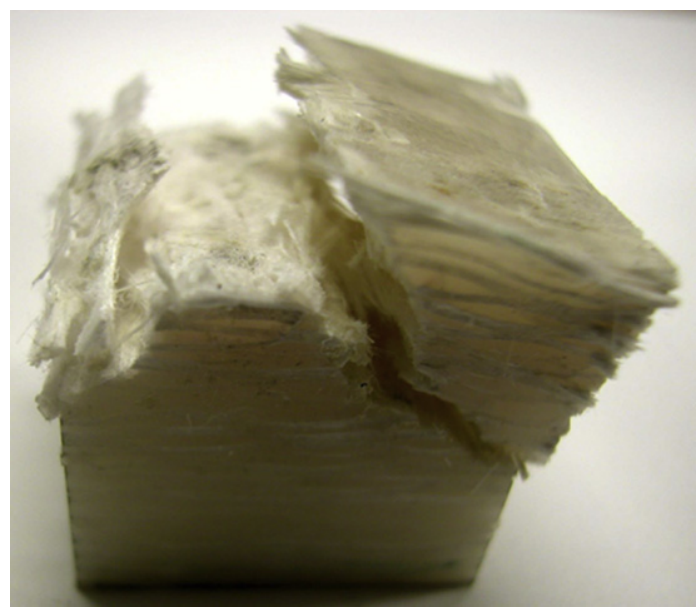

Fig. 8. Typical damage surface of a fractured specimen.

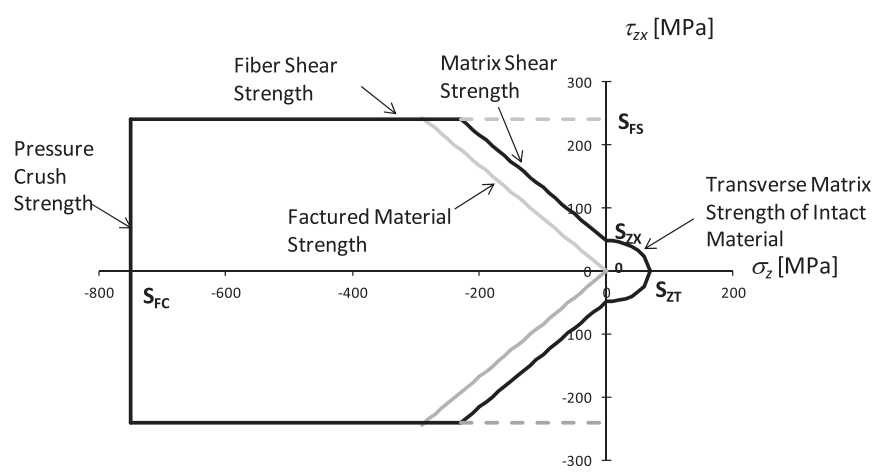

Fig. 9. Failure envelope associates with the through-thickness-stress components $\left(\sigma_{\mathrm{Z}}, \tau_{\mathrm{Zx}}\right)$ for an $\mathrm{S} 2 /$ Epoxy plain weave layer.

compared with their experimental counterparts. The outcome of this comparison was next used to both identify the stillundetermined material-model parameters and to provide validation for the present material model. The objective of this task is to evaluate the capability of utilizing the proposed progressive failure criteria within 3D brick element of LS-DYNA to model the structural response of composite plates subjected to high velocity ballistic impact conditions. Simulations of the ballistic impact of two S2Glass/Epoxy composite panels were conducted by accounting for the strain-rate sensitivity properties. Analyses were performed to predict and correlate the measured perforation limit velocity (V50) and damages in the composite plates subjected to fragment simulating projectile (FSP) impact testing. The analyzed ballistic problems were: (1) a $3.41 \mathrm{~kg} / \mathrm{m}^{2}$ composite plate of $30.5 \mathrm{~cm} \times$ $30.5 \mathrm{~cm} \times 1.8 \mathrm{~cm}$ subjected to 0.50 caliber FSP impact [32], and (2) a $1.18 \mathrm{~kg} / \mathrm{m}^{2}$ composite plate of $30.5 \mathrm{~cm} \times 30.5 \mathrm{~cm} \times 0.623 \mathrm{~cm}$ subjected to 0.30 caliber FSP impact.

The finite element models for the $1.18 \mathrm{~kg} / \mathrm{m}^{2}$ composite panel and the 0.30 caliber FSP are shown in Fig. 10. Only one quadrant of the composite panel and one quadrant of the FSP with chisel head were modeled due to the geometric and material symmetry. Both the plate and the projectile were modeled with 8-node brick elements with a single integration point. There were 24 layers of elements through the thickness.

The panel was placed over a rigid ring with a rigid body contact surface assumed between the plate and the ring. Initial velocity was provided to the impacter/FSP to start the analysis. The projectile was made out of AISI 4340 steel which was modeled as an elastoplastic material. An eroding contact algorithm provided within LS-DYNA together with the integrated failure model was used to simulate the contact and penetration between the projectile and the impact area of the plate. Note that the element erosion criterion is associated with the complete fiber failure in both plain weave yarn directions. All failed elements were deleted and the contact surfaces were automatically updated to the newly exposed layers of material.

The material properties for an S2-Glass/Epoxy plain weave composite layer and the AISI 4340 steel FSP, listed in Table 1, were used to perform the simulation. The composite-material quasistatic elastic properties were obtained from the MIL-HDBK-17-3E handbook [33]. The axial tensile and compressive strength values of the plain weave S2-glass/epoxy composite were obtained from the routine tensile and compressive tests, while the punch shear and crush strengths were determined from the LCCT tests described in the previous section. Note that the composite layer strengths related to the fiber failure, which include the in-plane tensile and compressive strengths as well as the out-of-plane punch shear and crush strengths, have strong effects on the composite ballistic behavior. 

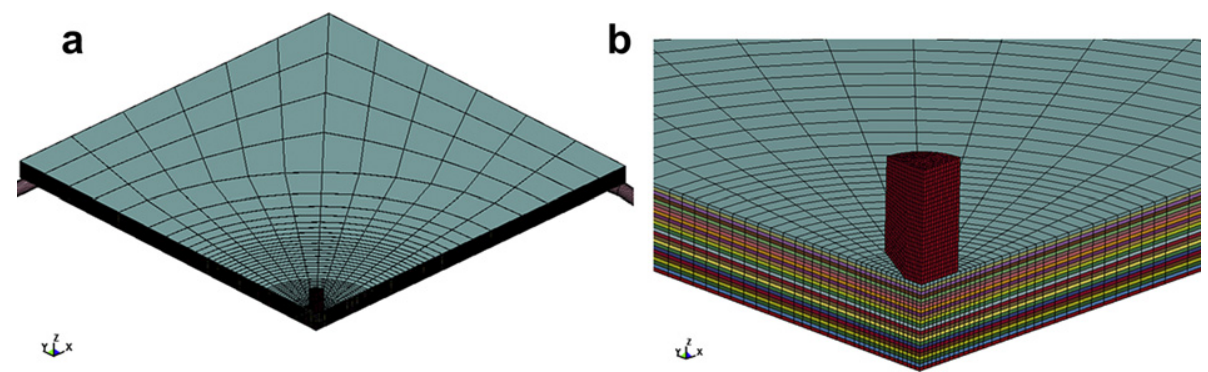

Fig. 10. Finite element model for a composite panel and an FSP impacter, (a) Full view, and (b) Close-up of impact area.

It was described in Section 3.1 that the strain-rate dependent axial stress-strain data provided in Ref. [28] for the current S2glass/epoxy plain weave laminate can be reasonably represented by the rate effect parameters of $C_{1}=0.03$ and $C_{2}=0.03$, which were used in the current simulations of the test cases (1) and (2). This should provide an improvement over the earlier correlation studies of the test cases of (1) provided in Ref. [1] for which the strain-rate consideration was only limited to the composite strength while the rate effect of elastic modulus was neglected due to the lack of data.

The post failure damage softening parameter, $m=4$, was chosen due to the fact that it usually provided the best agreement between the computed and the experimentally measured values of the ballistic limit V50 for several cases reported in previous studies [1-3]. Additionally, it is evidently demonstrated that $m=4$ provided the best agreement between the computed and the experimentally measured value for the ballistic limit V50 for the first case of the $3.41 \mathrm{~kg} / \mathrm{m}^{2}$ plate subjected to 0.50 Caliber FSP impact.

The set of material properties listed in Table 1 were then used to predict the $\mathrm{V} 50$ of the $1.18 \mathrm{~kg} / \mathrm{m}^{2}$ composite plate subjected to impact by a 0.30 caliber FSP. Fig. 11 shows the time histories of projectile velocity for three values of initial impact velocity. Note that the initial velocity is negative (downward) and the rebounding velocity is positive, which is not shown in the figure for clarity. It is seen from Fig. 11 that the predicted V50 of the second panel is about $1345 \mathrm{fps}(410 \mathrm{~m} / \mathrm{s})$, which is about $6 \%$ higher than the experimental value of $1270 \mathrm{fps}(387 \mathrm{~m} / \mathrm{s})$.

For the second series of ballistic tests, the damage zones were visible on each target to compare the relative sizes of damage area. To increase the visibility and contrast, targets were placed against a backlit box, and the images of each impact area were captured. The visible area of each damage zone was quantified using AxioVision image processing software (Carl Zeiss, Inc.) [34]. Fig. 12

Table 1

Material properties used for dynamic analysis.

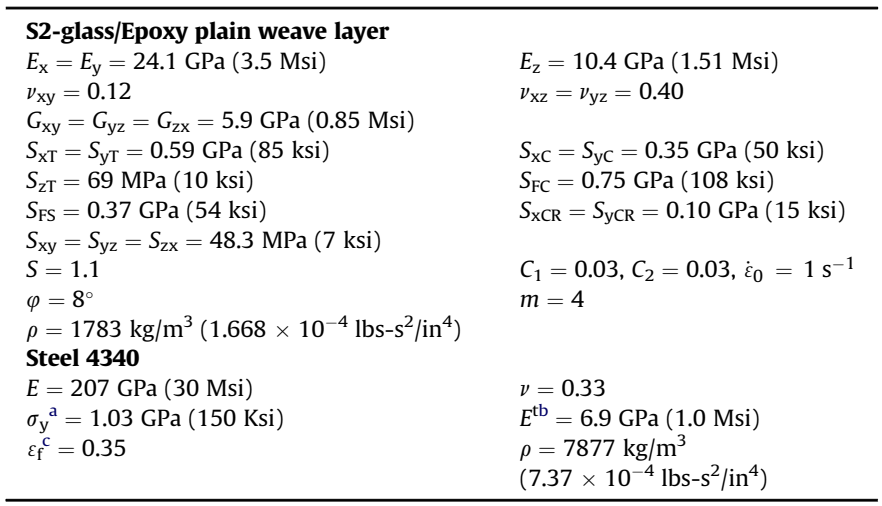

\footnotetext{
a Yield stress.

b Plastic tangent modulus.

c Failure strain.
}

shows a typical back lit image of a damaged target subjected to an impact velocity of $342 \mathrm{~m} / \mathrm{sec}$. The back lit image is compared to the image obtained by using the well-known C-scan with satisfactory result. In Fig. 13, the measured damage areas are plotted with the associated impact velocities.

To determine an optimal value for the stress concentration parameter for delamination propagation, $S$, a comparison is made between the computed and experimentally measured delamination areas for the first test series. The effect of different $S$ values on the delamination areas as function of the impact velocities is shown in Fig. 13. Based on the results displayed in this figure, the value of $S=1.1$ clearly provides the best match of predicted damage areas to the experimental data for the impact velocities ranging from partial penetration to complete perforation. Note that the value of $S=1.1$ was also used in the previous ballistic simulations of the first case and matched the experimental data of delamination areas with reasonable accuracy.

It is important to point out that the main goal of this research is to develop a robust modeling tool which can effectively be used to simulate the ballistic capacity of plain weave laminates of various configurations subjected to impact of different projectiles with a wide range of velocities. The accuracy of the model was validated by providing blind predictions for a series of glass/epoxy laminates of various areal densities subjected to impact by several types of projectiles with measured V50 and residual velocities as reported in Yen and Morris [35] and [4]. Note that a set of material parameters was obtained for the composite by following the procedure described in this paper based on a set of data of a composite system. This was then used for predicting the remaining test cases. The predicted V50s and residual velocities are within $10 \%$ of the

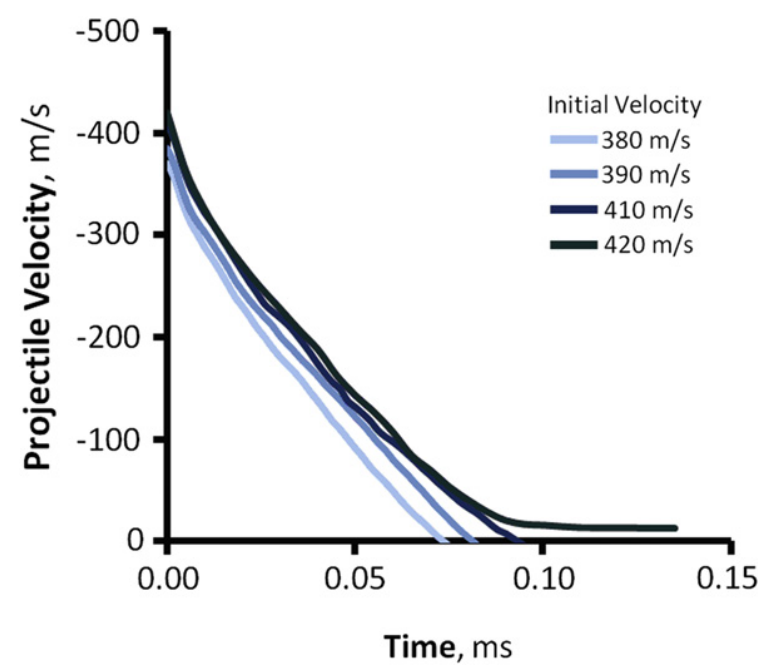

Fig. 11. Computed time histories of projectile velocity for an S2-Glass/Epoxy composite subjected to 0.22 caliber FSP impact. 

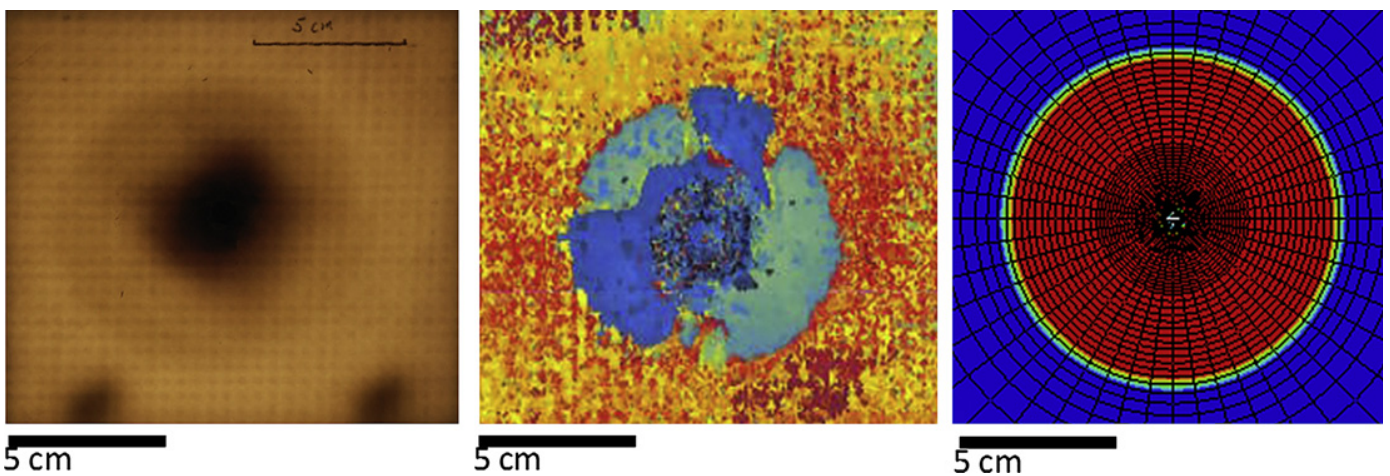

Fig. 12. Predicted maximum delamination area in the impacted composite panel comparing with the damage area of a tested panel using light inspection and C-scan.

associated experimental data. The modeling accuracy has been accomplished by considering strain-rate effects for the fiber failure modes but assuming rate independency for the matrix dominated failure modes with the introduction of a scale factor " $\mathrm{S}$ " for modeling the delamination zone, as described in Section 2.

The composite model has also been incorporated in LS-DYNA as the Material 162 (MAT162) since 2003 [36]. The accuracy of the model has been reported by numerous users, e.g. Refs. [37-39]. For examples, the model was used in Deka et al. [36,37] to predict damage progression in a series of composite panels subjected to single- and multi-hit impact. Good agreement between the numerical and experimental results was attained in terms of predicting ballistic limit, delamination and energy absorption of $\mathrm{E}$ glass/PP laminate.

In summary, good correlation between the predicted and experimental results on the ballistic capacities of various composite laminates seems to indicate that the model provides proper prediction of the overall energy dissipation during ballistic events which are dominated by the fiber failure modes. Although the current simplified approach provides satisfactory results on predicting the delamination behavior, the rate effect on matrix dominated modes can be readily included in the model for rate sensitive matrix materials. The model can also incorporate the well-known cohesive element approach for better modeling of the delamination progression. However, this usually requires additional characterization in terms of the interface fracture parameters including the peak strength, critical energy release rate and the associated strain-rate sensitivity properties for the three fracture modes. Furthermore, cohesive elements must be inserted at every

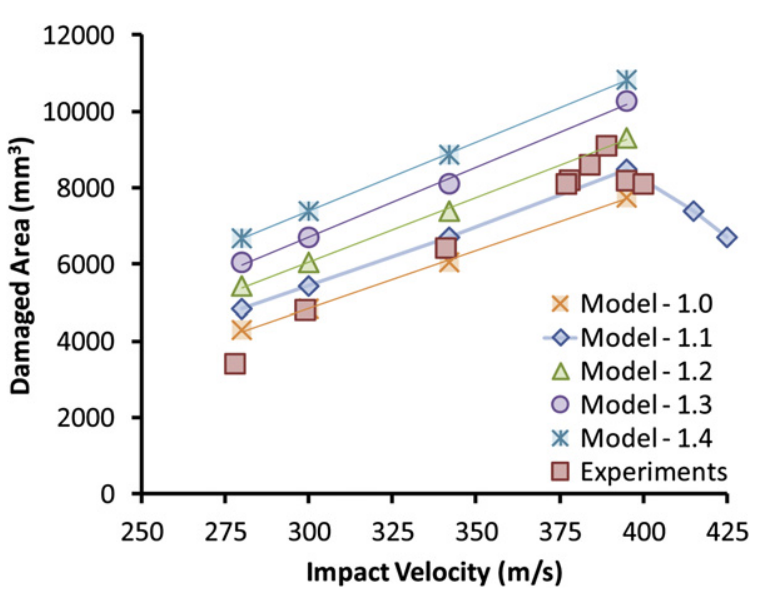

Fig. 13. Comparison of predicted delamination area due to various impact velocities with measured data for various $\mathrm{S}$ values. inter-layer interface in the finite element model to simulate the laminate delamination. Finally, the use of 3D photogrammetry techniques to acquire the time history of the panel deflection profile during a ballistic event will provide an opportunity for further validation of the models accuracy in future studies.

\section{Conclusions}

A strain rate dependent lamina model based on continuum damage mechanics has been successfully developed and implemented within LS-DYNA for modeling the progressive failure behavior of plain weave composite layers. It can be used to effectively simulate the fiber failure and delamination behavior under high strain-rate and high-pressure ballistic impact conditions. The integrated code was successfully utilized to predict the ballistic limit velocity of composite laminates subjected to high velocity ballistic impact conditions. Simulations of ballistic impact of composite panels have been conducted by taking into account the strain-rate sensitivity of material response. The strain rate effect will need further investigation by experimentally characterizing the rate dependent behavior of various composite materials. Correlation for impact damage such as delamination area will also need to be conducted when the test data is available in the future.

The present composite material model can provide insight into the damage development and progression that occurs during the ballistic impact of composite panels. By identifying specific damage mechanisms that occur, reinforcement schemes can be determined to suppress them, which may ultimately enhance the survivability of the designed protection systems.

\section{Acknowledgments}

Initiation of this work was supported by the U.S. Army Research Laboratory under Contract No. DAAD17-00-C-0059 when the author was working at Materials Sciences Corporation.

\section{References}

[1] Yen CF. Ballistic impact modeling of composite materials. In: Proceedings of the 7th International LS-DYNA Users Conference; May 19-21, 2002. Dearborn, MI.

[2] Yen CF. Modeling of composite materials under strain-rate loading conditions. In: Proceedings of the 18th Annual Technique Conference American Society of Composites, MB5-224; October 19-22, 2003. Gainesville, FL.

[3] Yen CF. Ballistic impact modeling of 3D woven composite materials. Presented at 16th Army Symposium on Solid Mechanics, May 4-7, 2003, Charleston, SC

[4] Yen CF. Modeling of composite material behavior for blast and ballistic impact. In: Proceedings of ESDA 2006, 8th Biennial ASME Conference on Engineering Systems Design and Analysis; July 4-7, 2006. Torino, Italy.

[5] Abrate S. Impact on laminated composites: recent advances. Appl Mech Rev 1994; V47:517-43.

[6] Richarson MOW, Wisheart MJ. Review of low-velocity impact properties of composite materials. Composites 1996;27A:1123-31. 
[7] Choi HY, Chang FK. Impact damage threshold of Laminated composites. In: Failure criteria and analysis in dynamic response, AMD, vol. 107. Dallas, TX: ASME Applied Mechanics Division; November 1990. p. 31-5.

[8] Davies GAO, Zhang X. Impact damage prediction in carbon composite structures. Int J Impact Eng 1995;16:149-70.

[9] Chang FK, Chang KY. A progressive damage model for laminated composites containing stress concentration. J Compos Mater 1987;21:834-55.

[10] Matzenmiller A, Lubliner J, Taylor RL. A constitutive model for anisotropic damage in fiber-composites. Mech Mater 1995;20:125-52.

[11] William K, Vaziri R. Finite element analysis of the impact response of CFRP composite plates. In: Scott Murray L, editor; 1995. Proceedings of the ICCM11 , pp. 532-654.

[12] Van Hoof J, Woeswick MJ, Straznicky PV, Bolduc M, Tylko S. Simulation of ballistic impact response of composite helmets. In: Proceedings of the 5th International LS-DYNA Users Conference; 1998.

[13] Ladeveze P. Multiscale computational damage modelling of laminate composites. In: Sadowski T, editor. Multiscale modelling of damage and fracture processes in composite materials. Springer-Verlag; 2005. p. 309.

[14] Ladeveze P, Lubineau G, Violeau D. A computational damage micromodel of laminated composites. Int J Fracture 2006;137:139-50.

[15] Grujicic M, He T, Marvi H, Cheeseman BA, Yen CF. A comparative investigation of the use of laminate-level meso-scale and fracture-mechanics-enriched meso-scale composite-material models in ballistic-resistance analyses. J Mater Sci 2010;45(12):3136-50.

[16] Harding J, Ruiz C. The mechanical behaviour of composite materials under impact loading. In: Key Engineering Materials, vol. 141-143. Switzerland: Trans Tech Publications; 1998. 403-426.

[17] Al-Hassani STS, Kaddour AS. Strain rate effects on GRP, KRP and CFRP composite laminates. In: Key Engineering Materials, vol. 141-143. Switzerland: Trans Tech Publications; 1998. 427-452.

[18] Harding J. The high-Speed punching of woven-Roving glass-reinforced composites. In: Inst Phys Conf Ser No. 47 [Chapter 3]. Bristol and New York: The Institute of Physics; 1979. pp. 318-330.

[19] Welsh LM, Harding J. Effect of strain rate on the tensile failure of woven reinforced polyester resin composite; 1985 . Proc. DYMAT 85, Int. Conf. On Mech. And Physical Behaviour of Materials Under Dynamic Loading, Jour de Physique, Colloque C5, pp. 405-414.

[20] Tsai SW, Wu EM. A general theory of strength of anisotropic materials. J Compos Mater 1971;5:58.

[21] Hashin Z. Failure criteria for unidirectional fiber composites. J Appl Mech 1980;47:329-34.

[22] Sun CT, Quinn BJ, Oplinger DW. Comparative evaluation of failure analysis methods for composite laminates. DOT/FAA/AR-95/109. Washington D.C: DOT Technical Report, Office of Aviation Research; 1996.

[23] Chatterjee SN. A Coulomb-Mohr type criterion for matrix mode failure in a lamina. Thirteenth Volume, ASTM STP 1242. In: Hooper SJ, editor. Composite materials: testing and design. American Society for Testing and Materials; 1997. p. 237-56.

[24] Puck A, Schurmann H. Failure analysis of FRP laminates by means of physical based phenomenological models. Compos Sci Technol 1998;58:1001-10.

[25] Davila CG, Camanho PP. Failure criteria for FRP laminates in plane stress, NASA/TM-2003-212663; NASA Technical Report. Hampton, VA: Langley Research Center; November 2003.

[26] Cantwell WJ, Morton J. The impact resistance of composite materials a review. Composites 1991;V22:347-62.

[27] Harding J, Welsh LM. Tensile testing technique for fibre-reinforced composites at impact rates of strain. J Mater Sci 1983;V18:1810-26.

[28] Song B, Chen W, Weerasooriya T. Quasi-static and dynamic compressive behaviors of a S-2 Glass/SC 15 composite. J Compos Mater 2003;V37: 1723-43.

[29] Yen CF, Cassin T, Patterson J, Triplett M. Progressive failure analysis of thin walled composite tubes under low energy impact. In: 39th AIAA Structures, Structural Dynamics, and Materials Conference; 1998a.

[30] Yen CF, Cassin T, Patterson J, Triplett M. Progressive failure analysis of composite sandwich panels under blast loading. In: Structures under extreme loading conditions, vol. 361. New York: ASME PVP; 1998b. pp. 203-216.

[31] Collin TA. Transverse compressive behavior of unidirectional carbon fiber reinforced plastics. Composites; May 1974:108-16.

[32] Yen CF, Caiazzo AA. Design methodology and validation for multifunctional composite armor. MSC Technical Progress Report. Aberdeen Proving Ground MD: U.S. Army Research Laboratory; July 2002. Contract No. DAAD17-01-C0111.

[33] MIL-HDBK-17-3E. In: MIL-HDBK-17-3E. Polymer matrix composites: material properties, vol. 2. West Conshohocken, PA: ASTM International; 2002.

[34] Yu J, Brennan R, Quabili A. Ballistic characterization of composite panels. ARL internal report; (Internal ARL Report) Aberdeen Proving Ground, MD October, 2011.

[35] Yen CF, Morris A. Blast/ballistic impact damage evaluation of marine composite structures. MSC TFR IH19, NSWCCD, Contract No. 5007-203-45/02. West Bethesda, MD: Naval Surface Warfare Center Carderock Division (NSWCCD); January 2003.

[36] Yen CF. User's manual for LS-DYNA Mat162 unidirectional and plain weave composite progressive failure models. provided to. Livermore, CA: Livermore Software Technology Corporation; 2003.

[37] Deka LJ, Bartus SD, Vaidya UK. Multi-site impact response of S2-glass/epoxy composite laminates. Compos Sci Technol 2009;69:725-35.

[38] Deka LJ, Bartus SD, Vaidya UK. Damage evolution and energy absorption of Eglass/polypropylene laminates subjected to ballistic impact. J Mater Sci 2008; 43:4399-410.

[39] Kevin A, Brown KA, Brooks R, Warrior NA. The static and high strain rate behaviour of a commingled E-glass/polypropylene woven fabric composite. Compos Sci Technol 2010;70:272-83. 